\section{Occupational carcinogen exposure in Canada}

\author{
Martie Van Tongeren
}

My colleague Professor John Cherrie once said that we know more about the number of birds breeding in British meadows each year (see http://jncc.defra. gov.uk/pdf/BBSreport12_web.pdf) than the number of workers exposed to carcinogens in the workplace. It is clearly important to monitor bird populations, but I would consider it of at least equal importance to know what hazardous agents workers are exposed to. However, there are few data sources that can provide accurate information on the prevalence of occupational exposures.

In the early 1990s, Timo Kauppinen at the Finnish Institute of Occupational Health led a team that aimed to estimate the prevalence of occupational exposure in 55 industries for 15 member states of the European Union (EU). ${ }^{1}$ This CAREX system has been extensively used in surveillance and burden of disease studies as well as by the International Agency for Research on Cancer (IARC) within the Monograph series. Since the publication of the original CAREX system some countries have been added to CAREX (Estonia, Latvia, Lithuania, the Czech Republic) $^{2}$ while estimates have been updated for some countries including Italy). ${ }^{3}$ CAREX was adapted for several countries in Central America, ${ }^{4} 5$ while researchers in New Zealand recently also developed a CAREX system. ${ }^{6}$

In this issue of the OEM, Peters et $a l^{7}$ describe the CAREX-CANADA system. In addition to estimates of the prevalence of exposure, Peters and her coworkers have provided, where possible, estimates of the intensity of the exposure.

Why is it important to have good estimates of the prevalence and intensity of exposure?

Occupational diseases still represent a significant health burden as well as a financial cost for public and private social protection systems. Rushton et $a l^{8}$ estimated that in Great Britain about 8000 cancer deaths and 13000 cancer registrations per year could be attributed to past

Correspondence to Dr Martie Van Tongeren, Centre for Human Exposure Science (CHES), Institute of Occupational Medicine, Research Avenue North, Riccarton, Edinburgh EH14 4AP, UK; Martie. VanTongeren@iom-world.org occupational exposure to known and probable carcinogens. These represented $5.3 \%(8.2 \%$ men, $2.3 \%$ women $)$ of all cancer deaths recorded in Britain in 2005 and $4.0 \%$ (5.7\% men, $2.1 \%$ women) of all cancer registrations in 2004. Driscoll et $a l^{9}{ }^{10}$ estimated that worldwide in 2000 there were 386000 deaths from nonmalignant respiratory disease and 152000 cancer deaths from exposures experienced in the workplace. Other countries are currently doing similar studies, such as in Canada as reported by Peters et al, ${ }^{7}$ while we are working on a project to estimate the burden of disease from occupational exposures in Singapore (see http://www. iom-world.sg/our-services/research/ construct-healthsg/).

Good progress has been made over the past 30 or 40 years in reducing occupational exposures, at least in European and North-American countries. ${ }^{11}$ However, estimates provided by Peters et $a l^{7}$ for Canada, as well as by Carey et $a l^{12}$ for Australia and by us for Britain ${ }^{13}$ and the $\mathrm{EU}^{14}$ show that the prevalence of exposure to carcinogens is still high in certain industries, in particular for respirable crystalline silica, diesel exhaust fumes, ultraviolet radiation and shift work.

The impact of occupational exposure on the health of workers is very difficult to estimate accurately, in particular when dealing with chronic disease. Occupational disease registries and surveillance schemes are likely to suffer from under-reporting and hence burden of disease studies are complementary to occupational disease reporting schemes. Such burden of disease studies use information on exposure-response associations from epidemiological studies, information on background disease rates in the general population, and estimates of exposure to calculate the fraction of disease incidence and mortality that can be attributed to occupational exposures. Rushton $e t a l^{8}$ and Driscoll et $a l^{9}{ }^{10}$ used CAREX to obtain estimates of the prevalence of exposure in their burden of disease studies. Furthermore, we used CAREX in a recent project, funded by the European Commission, to estimate the health and socioeconomic impact of changes to the EU Carcinogen Directive (SHECAN-project; see http://www.OccupationalCancer.eu). In this project, in addition to estimating the current burden of disease from occupational exposure (due to past exposures), we also estimated the impact of current exposures on the future burden of disease (up to 2060), and predicted the health and socioeconomic impact of a number of changes made to the EU Carcinogen Directive. To estimate the impact of policy changes that affect exposure levels, such as implementation of exposure limits, detailed information on exposure intensity, including temporal and spatial variability, is required.

Despite some updates, the CAREX EU estimates are outdated, as it (1) provides estimates that relate mainly to the period 1990-1993, (2) does not cover all current EU countries, (3) does not include agents or work circumstances that have been classified as carcinogenic since the mid 1990 s and (4) does not include intensity of exposure.

This was also recognised during a workshop on occupational carcinogens organised by the European Agency for Safety and Health at Work (EU-OSHA) in Berlin on 3 and 4 September 2012, which concluded that: "Research efforts estimating the burden of occupational disease and building on the links between occupations and exposures, are very helpful for setting priorities for prevention and disease recognition and compensation. Efforts to update exposure data for such studies, for example CAREX... need broad support, including from European institutions." (https:// osha.europa.eu/en/seminars/workshop-oncarcinogens-and-work-related-cancer).

In order to develop cost-effective and efficient policies to reduce and manage the health risks from exposure to hazardous agents at the workplace, it is essential that high-quality and comprehensive information on prevalence as well as intensity of occupational exposure to such agents is available at regional, national and international level. The work carried out by Peters $e t a l^{7}$ reported in this issue and that by others, for example Carey et $a l^{12}$ in a previous issue in this journal, is therefore very important. There are clearly limitations to any approach that aims to develop such estimates, as acknowledged by Peters et al, and further efforts should be encouraged to improve the accuracy of the estimates and to track any temporal changes in the prevalence as well as intensity of exposure. Considering the ongoing activities to estimate the global burden of disease, which includes the burden of occupational exposures, there is a clear need to coordinate a collection of worldwide data on prevalence and intensity of occupational exposure, not 
just of carcinogens, but of all hazardous substances used in the workplace.

Acknowledgements The author is grateful to John Cherrie for providing the link to the report on the Breeding Bird Survey of 2012 and for reviewing and commenting on the draft text.

\section{Competing interests None.}

Provenance and peer review Commissioned; internally peer reviewed.

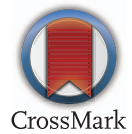

To cite Van Tongeren M. Occup Environ Med 2015;72:4-5.

Received 14 August 2014

Revised 24 September 2014

Accepted 14 October 2014

Published Online First 30 October 2014

\section{SLinked}

http://dx.doi.org/10.1136/oemed-2014-102286
Occup Environ Med 2015;72:4-5.

doi:10.1136/oemed-2014-102388

\section{REFERENCES}

1 Kauppinen T, Toikkanen J, Pedersen D, et al. Occupational exposure to carcinogens in the European Union. Occ Environ Med 2000;57:10-18.

2 Kauppinen T, Pajarskiene B, Podniece $Z$, et al. Occupational exposure to carcinogens in Estonia Latvia, Lithuania and the Czech Republic in 1997. Scand I Work Environ Health 2001:27:343-5.

3 Mirabelli D, Kauppinen T. Occupational exposure to carcinogens in Italy: an update of CAREX database. Int I Occup Environ Health 2005;11:53-63.

4 Partanen T, Chaves J, Wesseling C, et al. 2003 Workplace carcinogen and pesticide exposures in costa rica. Int I Occup Environ Health 2003;9:104-11.

5 Blanco-Romero LE, Vega LE, Lozano-Chavarría LM، et al. CAREX Nicaragua and Panama: worker exposures to carcinogenic substances and pesticides. Int J Occup Med Environ Health 2011;17:251-7.

6 't Mannetje A, McLean D, Glass D, et al. Occupational exposure to carcinogens in New Zealand. EPICOH 2014 challenges for occupational epidemiology in the 21st century. Chicago, USA, June 24-27 2014.

7 Peters C, Calvin G, Hall A, et al. CAREX Canada: an enhanced model for assessing occupational carcinogen exposure. Occ Environ Med 2015;72: 64-71.
8 Rushton L, Hutchings SJ, Fortunato L, et al. Occupational cancer burden in Great Britain. $\mathrm{Br}$ Cancer 2012;107:S3-7. doi: 10.1038/bjc.2012.112

9 Driscoll T, Nelson D, Steenland K, et al. The global burden of non-malignant respiratory disease due to occupational airborne exposures. Am J Indust Med 2005a;48:432-45.

10 Driscoll T, Nelson D, Steenland K, et al. The global burden of diseases due to occupational carcinogens. Am J Indust Med 2005b;48:419-31.

11 Creely K, Cowie H, Van Tongeren M, et al. Trends in inhalation exposure-a review of the data in the published scientific literature. Ann Occup Hyg 2007;51:665-78

12 Carey RN, Driscoll TR, Peter $\mathrm{S}$, et al. Estimated prevalence of exposure to occupational carcinogens in Australia (2011-2012). Occ Environ Med 2014;71:55-62.

13 van Tongeren $\mathrm{M}$, Jimenez $A S$, Hutchings $\mathrm{SJ}$, et al. Occupational cancer in Britain. Exposure assessment methodology. Br J Cancer 2012;107:S18-26. doi:10.1038/bjc.2012.114

14 van Tongeren $\mathrm{M}$, Hutchings $\mathrm{S}$, Gorman $\mathrm{Ng} \mathrm{M}$, et al. The SHEcan project: health and socio-economic impacts for changes to the carcinogen directive for some process generated substances. EPICOH 2.0.13 Improving the impact. Utrecht, The Netherland, 18-21 June 2013. 